\title{
Demonstration of a Consistent Relationship between Dual-Frequency Reflectivity and the Mass-Weighted Mean Diameter in Measurements of Frozen Precipitation from GCPEX, OLYMPEX, and MC3E 0
}

\author{
George Duffy, ${ }^{\mathrm{a}, \mathrm{b}}$ Greg Mcfarquhar, ${ }^{\mathrm{c}, \mathrm{d}}$ Stephen W. Nesbitt, ${ }^{\mathrm{e}}$ and Ralf Bennartz ${ }^{\mathrm{a}, \mathrm{f}}$ \\ ${ }^{a}$ Department of Earth and Environmental Sciences, Vanderbilt University, Nashville, Tennessee \\ ${ }^{\mathrm{b}}$ Jet Propulsion Laboratory, California Institute of Technology, Pasadena, California \\ ${ }^{\mathrm{c}}$ Cooperative Institute for Mesoscale Meteorological Studies, University of Oklahoma, Norman, Oklahoma \\ ${ }^{\mathrm{d}}$ School of Meteorology, University of Oklahoma, Norman, Oklahoma \\ ${ }^{\mathrm{e}}$ Department of Atmospheric Sciences, University of Illinois at Urbana-Champaign, Urbana, Illinois \\ ${ }^{\mathrm{f}}$ Space Science and Engineering Center, University of Wisconsin-Madison, Madison, Wisconsin
}

(Manuscript received 9 June 2020, in final form 14 May 2021)

\begin{abstract}
The retrieval of the mass-weighted mean diameter $\left(D_{m}\right)$ is a fundamental component of spaceborne precipitation retrievals. The Dual-Frequency Precipitation Radar (DPR) on the Global Precipitation Measurement (GPM) satellite is the first satellite to use dual-wavelength ratio measurements-the quotient of radar reflectivity factors $(Z)$ measured at $\mathrm{Ku}$ and $\mathrm{Ka}$ wavelengths - to retrieve $D_{m}$. While it is established that DWR, being theoretically insensitive to changes in ice crystal mass and concentration, can provide a superior retrieval of $D_{m}$ compared to $Z$-based retrievals, the benefits of this retrieval have yet to be directly observed or quantified. In this study, DWR $-D_{m}$ and $Z-D_{m}$ relationships are empirically generated from collocated airborne radar and in situ cloud particle probe measurements. Data are collected during nine intensive observation periods (IOPs) from three experiments representing different locations and times of year. Across IOPs with varying ice crystal concentrations, cloud temperatures, and storm types, $Z-D_{m}$ relationships vary considerably while the DWR $-D_{m}$ relationship remains consistent. This study confirms that a DWR $-D_{m}$ relationship can provide a more accurate and consistent $D_{m}$ retrieval than a $Z-D_{m}$ relationship, quantified by a reduced overall RMSE ( 0.19 and $0.25 \mathrm{~mm}$, respectively) and a reduced range of biases between experiments ( 0.11 and $0.32 \mathrm{~mm}$, respectively).
\end{abstract}

KEYWORDS: Aircraft observations; In situ atmospheric observations; Measurements; Radars/Radar observations; Remote sensing; Satellite observations

\section{Introduction}

Satellite radars are used extensively for global studies of precipitation. There have been three cloud and precipitation satellite radar missions and each has provided unique capabilities that allowed for historic advances in the understanding of precipitation. First, the Tropical Rainfall Measuring Mission (TRMM; Kummerow et al. 2000) Ku-band Precipitation Radar (PR) provided the first spaceborne vertical profiles of precipitation over the tropics. These measurements have been used as primary data in over 100 studies from multiple fields of Earth science (Li et al. 2019). Second, the CloudSat Cloud Profiling Radar (CPR; Stephens et al. 2004; Tanelli et al. 2008) provided the first spaceborne vertical profiles of precipitation at high latitudes using a highly sensitive W-band radar, leading to the first measurements of snowfall over

Supplemental information related to this paper is available at the Journals Online website: https://doi.org/10.1175/JAS-D-200174.s1.

Corresponding author: George Duffy, george.s.duffy@gmail.com remote regions such as Greenland (Bennartz et al. 2019), Antarctica (Palerme et al. 2014; Souverijns et al. 2018), and the global oceans (Liu 2009; Hiley et al. 2011; Behrangi et al. 2014; Kulie et al. 2016; Duffy and Bennartz 2018; Milani et al. 2018). The Global Precipitation Measurement (GPM; Hou et al. 2014) Dual-Frequency Precipitation Radar (DPR) is the third and most recent satellite precipitation radar. The DPR is a combination of two radars, one at $\mathrm{Ku}$ band $(13.6 \mathrm{GHz})$ and one at $\mathrm{Ka}$ band $(35.5 \mathrm{GHz})$, arranged to provide collocated measurements. These radar measurements can be combined to create a novel satellite measurement, the dual-wavelength ratio (DWR; see the appendix for a complete list of acronyms in this paper) given by

$$
\mathrm{DWR}=10 \log _{10}\left(Z_{1} / Z_{2}\right)
$$

with $Z_{1}$ and $Z_{2}$ representing radar reflectivity factors $(Z)$ with different wavelengths. DWR is sometimes referred to as the "dual-frequency ratio" (DFR; Liao et al. 2016). For the rest of this paper, $Z$ will refer to measured single-wavelength radar factors in general, $Z_{\mathrm{Ku}}$ and $Z_{\mathrm{Ka}}$ will specifically refer to the $Z$ measured at the Ku and Ka wavelengths of the DPR, and DWR will inherently refer to the DWR constructed from $Z_{\mathrm{Ku}}$ and $Z_{\mathrm{Ka}}$, 
Satellite algorithms use radar measurements to retrieve the mass-weighted mean diameter $\left(D_{m}\right)$ of liquid and frozen precipitation in retrieval algorithms, where

$$
D_{m}=\frac{\int_{D_{\min }}^{D_{\max }} n(D) m(D) D d D}{\int_{D_{\min }}^{D_{\max }} n(D) m(D) d D}
$$

with $m(D)$ representing ice particle mass as a function of particle size, $n(D)$ representing a measured or modeled ice particle number distribution function, $D$ representing a one-dimensional measurement of ice particle size, and $D_{\min }$ and $D_{\max }$ representing the sizes of the largest and smallest ice particles considered for the particle size distribution (PSD). The $m(D)$ should not be confused with the mass distribution function that often shares the same notation. Parameter $D_{m}$ is valuable and can be used as a characteristic dimension to understand microphysical processes and storm structure (Mroz et al. 2018; Akiyama et al. 2019; Huang et al. 2019; Ni et al. 2019). Also, $D_{m}$ is used to quantify PSDs in satellite precipitation retrieval algorithms (Seto et al. 2013; Wood et al. 2013; Williams et al. 2014; Borque et al. 2019). Satellite retrieval algorithms rely on assumed relationships between radar measurements and $D_{m}$. Specifically referring to DPR measurements in this study, these relationships will be referred to as $Z-D_{m}$ and DWR $-D_{m}$ relationships

The benefits of dual-frequency radar measurements for frozen precipitation retrievals are well studied. The $Z-D_{m}$ relationships can vary considerably with respect to changes in microphysical properties such as concentration, particle shape or density, while the DWR $-D_{m}$ relationships are much less sensitive to changes in ice crystal properties and are theoretically unaffected by changes in ice crystal concentration (Matrosov 1998; Liao et al. 2016; Leinonen et al. 2018a). Matrosov (1998) published the first method to directly retrieve snowfall precipitation rates and $D_{m}$ from dual-wavelength radar measurements, and improved snowfall precipitation retrieval methods were published as more scattering models became available (Liao et al. 2008, 2016; Leinonen et al. 2018a). Aside from the improvements for precipitation rate and $D_{m}$ retrievals, the addition of the Ka radar to the TRMM PR provides improvements to phase discrimination and light precipitation detection (Adhikari and Nakamura 2002; Kollias et al. 2007). There is also a growing body of literature demonstrating the utility of DWR observations at three or more wavelengths to provide simultaneous retrievals of PSD density and habit (Kneifel et al. 2011; Leinonen and Szyrmer 2015; Mason et al. 2019; Tridon et al. 2019). These triplefrequency methods can be applied to satellite retrievals during coincident CloudSat and GPM measurements (Yin et al. 2017).

One central prediction of DWR- $D_{m}$ retrievals has yet to be addressed, however. If DWR $-D_{m}$ relationships are minimally impacted by cloud microphysics such as concentration and density, one can hypothesize a single DWR $-D_{m}$ relationship that should be observable in frozen clouds irrespective of cloud type or location. Such an empirical relationship between DWR and $D_{m}$ would be free of scattering modeling assumptions typically required to generate simulated reflectivities. A confidently invariant DWR$D_{m}$ relationship could reduce a source of error in precipitation retrievals. Data products that generate precipitation estimates from satellite radar measurements rely on just one or two sets of microphysical assumptions to describe all clouds on the planet. However, average microphysical properties are known to differ consistently with respect to different cloud types and regions (Colle et al. 2014; Um et al. 2015). Differences between assumed and true cloud properties could lead to regional biases in studies that assume satellite data products to be a globally uniform best estimate of truth, such as evaluations of snowfall in reanalysis model from CloudSat observations (Behrangi et al. 2016; Palerme et al. 2017). If it can be demonstrated that a DWR retrieval can minimize a bias in $D_{m}$ across different storms, it would prove that DWR retrievals of precipitation are not just more accurate and sensitive than their single-wavelength counterparts, but they are more globally consistent as well.

In this study, collocated airplane in situ and radar measurements gathered during three GPM field campaigns in different locations and meteorological conditions (deep convective clouds, continental winter storms, and winter storms modified by orography) are used to derive empirical $Z-D_{m}$ and DWR- $D_{m}$ relationships. The relationships are subsequently used to compare the uncertainty of $D_{m}$ retrieval methods across different environments. Experiments in this study are organized around three research questions: "Are DWR and $D_{m}$ better correlated than $Z$ and $D_{m}$ in measured frozen clouds, and if so, by how much?"; "How do $Z-D_{m}$ and DWR $-D_{m}$ empirical relationships for frozen precipitation vary between different environmental conditions?"; and "Does an empirical DWR $-D_{m}$ relationship provide a more accurate and consistent retrieval in frozen precipitation than an empirical $Z-D_{m}$ relationship, and if so, by how much?" For the purposes of this study, "environmental conditions" refer to the conditions that distinguish different sets of measurements from one another (e.g., temperature, cloud type, meteorological conditions). Note that these questions are phrased conservatively for the sake of assumed ignorance. It is generally accepted that DWR-based retrievals will be superior to $Z$-based retrievals, but the improvements have yet to be demonstrated or quantified with real-world data.

The process used to identify collocated in situ and reflectivity measurements is described in section 2 . The results using the collocated observations to answer the research questions are provided in section 3. The empirical DWR $-D_{m}$ relationship is also derived in section 3. This relationship has potential use in satellite retrieval algorithms and this application is discussed in section 4 . The findings of this study are summarized in section 5 .

\section{Generating a collocated $D_{m}-D W R$ dataset}

In this section, the steps taken to construct the collocated DWR $-D_{m}$ dataset are described. Experiments that collected the necessary data are described in section $2 \mathrm{a}$. The procedure to calculate $D_{m}$ from in situ observations of ice particles within a sample collection volume is provided in section $2 \mathrm{~b}$. The procedure to ensure consistency of DWR across different experiments is provided in section $2 \mathrm{c}$. The procedure used to match in situ and radar observations is provided in section $2 \mathrm{~d}$.

\section{a. $G V$ experiments}

The dataset of collocated radar and in situ measurements comes from three GPM Ground Validation (GV) experiments: 
the GPM Cold Season Precipitation Experiment (GCPEX; Skofronick-Jackson et al. 2015), the Midlatitude Continental Convective Clouds Experiment (MC3E; Jensen et al. 2016), and the Olympic Mountains Experiment (OLYMPEX; Houze et al. 2017). GCPEX studied winter snowstorms from January through February 2012 near Barrie, Ontario. MC3E studied springtime convective storms from April through June of 2011 near Lamont, Oklahoma. OLYMPEX studied winter orographic storms from November through December 2015 near the Olympic Peninsula in Washington. Periods during experiments when the aircraft were sampling storms are referred to as "intensive observation periods" (IOPs). Collocated measurements refer to periods of time when the radar and in situ aircraft were sampling similar volumes. IOPs in this study are denoted according to the first letter of the experiment, followed by two numbers representing the month, and two numbers representing the day. For example, the OLYMPEX 1 December 2016 IOP is referred to as “O1201.' Exactly three IOPs from each experiment provide satisfactory data within the collocation criteria for this study. Collocation criteria are defined in section 2d. Flight paths of the in situ and radar aircraft that visualize collocated measurements during each IOP are provided in the online supplement.

\section{b. $D_{m}$ measurements}

As mentioned in the introduction, $D$ refers to any onedimensional measurements of ice particle size. In this study, ice particles within a sample volume are measured by imaging probes installed on the UND Citation. The measured size of an ice particle $\left(D_{\text {meas }}\right)$ is defined as the minimum diameter of a circle that completely encompasses an ice particle image, or as the minimum diameter of a circle that completely encompasses a reconstructed image of a partially imaged ice particle (Heymsfield and Parrish 1978). PSDs were determined using the system for optical array probe data analysis (SODA) processing code at NCAR that corrects for out of focus circular particles and eliminates shattered artifacts The binned data are available at $1 \mathrm{~s}$ resolution. Particle images from a Two-Dimensional Cloud Imaging Probe (2D-C), a 2D Stereo (2D-S), and a Cloud Imaging Probe (CIP) are used to determine $n\left(D_{\text {meas }}\right)$ for $D_{\text {meas }}<1 \mathrm{~mm}$ depending on the project. Particle images from a High-Volume Precipitation Spectrometer version 1 (HVPS1) or High Volume Precipitation Spectrometer version 3 (HVPS3) are used to determine $n\left(D_{\text {meas }}\right)$ for $D_{\text {meas }}>1 \mathrm{~mm}$. The 2DC and CIP were used during GCPEX and MC3E, while the 2DS was used OLYMPEX. The HVPS1 was used during MC3E, while the HVPS3 was used during GCPEX and OLYMPEX.

The GPM-DPR algorithms (Seto et al. 2013; Chase et al. 2020) retrieve $D_{m}$ as a liquid equivalent diameter $\left(D_{\text {liq }}\right)$, the diameter of a liquid drop with the same mass of an ice particle of some $D_{\text {meas }}$. To make the results of this study applicable to GPM retrievals, $n\left(D_{\text {meas }}\right)$ is converted to $n\left(D_{\text {liq }}\right)$ before calculating $D_{m}$. The terms $D_{\text {liq }}$ and $D_{\text {meas }}$ are related through

$$
D_{\text {liq }}=\left(\frac{6 a}{\rho_{w} \pi}\right)^{1 / 3} D_{\text {meas }}^{b / 3},
$$

where $\rho_{w}$ represents the density of water and $a$ and $b$ are mass coefficient and exponent parameters used in power-law mass-diameter relationships $m\left(D_{\text {meas }}\right)=a D_{\text {meas }}^{b} ; a$ and $b$ are set to 0.007 and $2.2 \mathrm{~g} \mathrm{~cm}^{-2.2}$, respectively, following the Heymsfield et al. (2010) parameterization for unspecified convective or stratiform clouds. These parameters are chosen since they were also drawn from a combined experimental dataset representing different regions and temperatures. The $m(D)$ function used to calculate $D_{m}$ in Eq. (2) is derived from the density function for a spherical liquid water droplet:

$$
m(D)=\rho_{w} \frac{D^{3}}{6} .
$$

A goal of this study is to determine a general relationship between DWR and $D_{m}$ that is free from scattering assumptions, and the introduction of a mass-diameter assumption arguably detracts from this goal. A more objective relationship between DWR and $D_{m}$ would result if $D_{m}$ was calculated from $D_{\text {meas }}$, what could be considered a mass-weighted mean maximum particle dimension, though this relationship would still be dependent upon what definition of $D_{\text {meas }}$ used (Wu and McFarquhar 2016) and on the orientations of the threedimensional particles passing through the probe sample volume. However, such a measurement is rarely used in precipitation retrievals, so liquid equivalent $D_{m}$ is therefore preferred. Results in this study that are based on the Heymsfield et al. (2010) $m-D_{\text {meas }}$ relation may not be directly applicable to algorithms that utilize different $a$ and $b$ parameters. Different treatments of $D_{m}$ essentially amount to a scaling factor, however, and it would be a trivial matter to recalculate the results of this study with respect to any given mass assumption provided the same assumed $m-D_{\text {meas }}$ relation is applied to all particles regardless of shape; some mass calculation schemes dependent on particle habit (e.g., Jackson et al. 2012), particle area ratio (e.g., Baker and Lawson 2006), or particle size (e.g., Ding et al. 2020) do exist. For the rest of this paper, however, $D$ inherently refers to $D_{\text {liq. }}$.

\section{c. DWR measurements}

Radar measurements at $\mathrm{Ku}$ and $\mathrm{Ka}$ wavelength were obtained by either the High Altitude Wind and Rain Airborne Profiler (HIWRAP; Li et al. 2016), which was deployed on the NASA ER-2 high-altitude aircraft, or the Advanced Precipitation Radar (APR; Sadowy et al. 2003) 2 or 3, which was deployed on the DC-8 aircraft. The HIWRAP collected data during MC3E and OLYMPEX, while the APR collected data during GCPEX and OLYMPEX. The HIWRAP has scanning capabilities, but it just operated at nadir mode for the GV experiments. The HIWRAP has nominal $\mathrm{Ku}$ and $\mathrm{Ka}$ frequencies of 13.9 and $35.6 \mathrm{GHz}$, respectively. The HIWRAP has a minimum detectable reflectivity of 0 and $-5 \mathrm{~dB}$ at $\mathrm{Ku}$ and $\mathrm{Ka}$ wavelengths, respectively. The APR 2 and APR 3 consists of $\mathrm{Ku}$ and Ka scanning radars with nominal frequencies of 13.4 and $35.6 \mathrm{GHz}$, respectively, though just the nadir pointing $\mathrm{Ku}$ and $\mathrm{Ka}$ reflectivity scans are used in this study. The APR has a minimum detectable reflectivity of $5 \mathrm{~dB}$ at both $\mathrm{Ku}$ and $\mathrm{Ka}$ wavelengths. Initial radar gate widths were $30 \mathrm{~m}$ for APR measurements, $37 \mathrm{~m}$ for HIWRAP during OLYMPEX, and $75 \mathrm{~m}$ for HIWRAP during MC3E. For comparison with each other and GPM, radar profiles were 
rescaled to have a resolution as close to the 250-m gate width of the DPR as possible. Reflectivities were averaged as linear units before being converted to decibel reflectivities.

There are several phenomena unrelated to $D_{m}$ that can impact the measured DWR of a sample volume and introduce errors into an empirical DWR- $D_{m}$ relationship if not accounted for. As $Z_{\mathrm{Ku}}$ and $Z_{\mathrm{Ka}}$ fall near the minimum detectable reflectivity of precipitation radars along the edges of clouds (including the sides and the tops of clouds), the difference between $\mathrm{Ku}$ and $\mathrm{Ka}$ radar sensitivities can sometimes lead to large and unphysical positive or negative DWR. Cloud-edge DWR is easy to identify by sight, and measurements that appeared to be influenced by cloud-edge DWR were removed after the collocation process (section $2 \mathrm{~d}$ ). Attenuation, the decrease of measured reflectivity due to absorption from water and atmospheric gas, is stronger at $\mathrm{Ka}$ band than $\mathrm{Ku}$ band and can increase DWR along a radar path. Attenuation from gas should be on the order of tenths of a decibel (Chase et al. 2018). Supercooled liquid water that may exist in the path between the radar and in situ measurement can attenuate the radar and is therefore considered as a possible source of uncertainty in DWR. However, this effect has previously been considered ignorable for $Z_{\mathrm{Ka}}$ measurements in stratiform clouds (Matrosov 2007), including studies using OLYMPEX data (Chase et al.2018). Ku and Ka components of the HIWRAP and APR also had different calibration offsets that varied with each IOP, and the difference between these offsets leads to a DWR bias. This calibration error can be estimated by identifying regions where other sources of DWR have their minimum impact. Since these sources will most often only serve to increase DWR (negative DWR was only seen along the sides of clouds, and retrievals that caught these edges were rare), these regions are identified by retrieving the minimum DWR $\left(\mathrm{DWR}_{\min }\right)$ along each radar profile and the calibration error for each IOP was determined as the mode of $\mathrm{DWR}_{\min }$. Calibration errors estimated from each IOP are listed in Table 1, and these offsets are applied to all measurements in this study.

\section{d. Collocating DWR and $D_{m}$ measurements}

A nearest-neighbor algorithm is used to match the radar and in situ measurements to the same time series. The closest horizontal point of reflectivity is matched to the Citation aircraft location for every second of flight time. The in situ and radar measurements are averaged into discrete $10 \mathrm{~s}$ intervals corresponding to an in situ measurement path of little more than a kilometer, given the true speed of the aircraft. The $10 \mathrm{~s}$ time offers a good compromise between having an adequate statistical sample and resolving fine-scale variability of cloud structure (McFarquhar et al. 2007). "Collocated data" are defined as matched in situ and radar measurements with spatial distance $(d r)$ and time difference $(d t)$ that fall below boundaries chosen by a sensitivity test. This test aims to maximize the number of data points $\left(N_{\text {meas }}\right)$ and the average rank correlation coefficient $(\bar{\rho})$ between DWR and $D_{m}$ as calculated from all 9 IOPs. The sensitivity test is visualized in Fig. 1 . We use $\bar{\rho}$ as the correlation coefficient since it can be used to identify nonlinear relationships between two variables and the relationship between DWR and $D_{m}$ is predicted to be nonlinear
TABLE 1. Estimated calibration error subtracted from DWR measurements during each IOP used in this experiment. IOPs are listed twice if two radar aircraft were taking measurements on the same day.

\begin{tabular}{lc}
\hline \hline \multicolumn{1}{c}{ IOP } & Estimated calibration error $(\mathrm{dB})$ \\
\hline G0212 & 1.03 \\
G0224 & 0.24 \\
M0425 & 0.01 \\
M0520 & 0.17 \\
M0523 & -0.52 \\
O1201 (HIWRAP) & 0.23 \\
O1212 (HIWRAP) & 0.28 \\
O1201 (APR) & 0.16 \\
O1212 (APR) & 0.23 \\
O1218 (APR) & 0.20 \\
\hline
\end{tabular}

across the full span of measured DWR (Liao et al. 2016). A $d t=3.5 \mathrm{~min}$ and $d r=12 \mathrm{~km}$ are chosen as boundaries that provide an agreeable trade-off between $\bar{\rho}$ and $N_{\text {meas. }}$. Any data with $d t$ less than $10 \mathrm{~s}$ are removed to eliminate the possibility of reflection from the aircraft being included in the dataset. Data are removed if $T>-3^{\circ} \mathrm{C}$ to focus on freezing precipitation. Data with clearly identifiable cloud-edge DWR influence are removed on sight. During O1201, a collocation error was identified at 2319 UTC (figure not shown) whereby a few pairs of collocated DWR and $D_{m}$ were likely representing dissimilar PSDs due to cloud inhomogeneity, and they were removed since they adversely impacted results as outliers in empirical regressions.

The final collocated dataset consists of a coincident time series of $D_{m}$ and DWR, an example of which during G0224 is presented in Fig. 2. The time series of the two measurements are visibly similar, indicating that the matching procedure between these independent measurements was a success. The $D_{m}$ and DWR observed during this IOP, up to $10 \mathrm{~mm}$ and $11 \mathrm{~dB}$, corresponds with the range of measurements seen during the experiment.

\section{Results}

\section{a. Fit functions for empirical data}

Empirical relationships between parameters are derived from regressions through collocated data that follow predetermined fit functions. Measured relationships between collocated $Z$ and $D_{m}$ have been fit to a power law in previous studies (Matrosov and Heymsfield 2017; Skofronick-Jackson et al. 2019). The same convention is followed in this study, with

$$
D_{m}=c_{1} Z_{\mathrm{Ku}}^{c_{2}},
$$

where $c_{1}$ and $c_{2}$ represent the $Z-D_{m}$ relationship parameters. The $Z-D_{m}$ relationships are derived in linear space, but they are plotted in $\mathrm{dB} Z$.

The relationship between DWR and $D_{m}$ has not been derived from field observations before this study, but it has been simulated by applying scattering models to assumed size distributions (Liao et al. 2016). When these relationships are cast as functions of DWR, they are characterized with an 

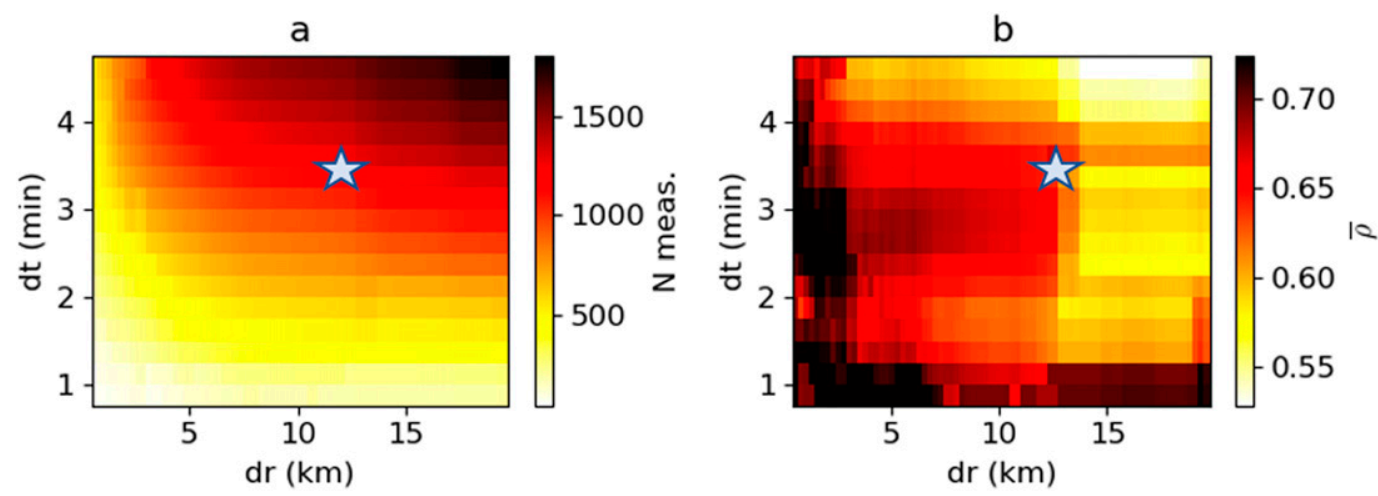

FIG. 1. A visual representation of the sensitivity test used to define collocation through $d r$ and $d t$ between in situ microphysical and radar data. (a) $N_{\text {meas }}$ and (b) $\bar{\rho}$ (both shaded) as a function of $d t(\mathrm{~min})$ and $d r(\mathrm{~km})$ for all nine IOPs considered in this study. The star indicates the $d r-d t$ threshold used to define collocated observations in this study.

origin approaching 0 , a negative curvature at lower DWR, and a positive curvature at high DWR. To allow for this change of inflection, a fit function defined by

$$
D_{m}=c_{3} \mathrm{DWR}^{c_{4}}+c_{5} \mathrm{DWR}^{c_{6}}
$$

is used to represent the relationships where $c_{3}, c_{4}, c_{5}$, and $c_{6}$ represent the DWR $-D_{m}$ relationship parameters.

Since $D_{m}$ below $0.2 \mathrm{~mm}$ were not observed in this study, any pure application of this regression results in $c_{4}$ minimizing to infinitesimally low values in an attempt to form an unphysical $y$ intercept. To ensure the function follows the shape suggested by the theoretical scattering models, Eq. (6) is bounded with $c_{3}>0 \mathrm{~mm} \mathrm{~dB}^{-c_{4}}, 0.25<c_{4}<1, c_{5}>0 \mathrm{~mm} \mathrm{~dB}^{-c_{6}}$, and $c_{6}>1.0$. In subsections that just consider collocated data from specified experiments, IOPs, or temperature ranges, regressions are only plotted within the bounds of $Z$ and DWR in the data subsets.

\section{b. Empirical relationships between radar measurements and $D_{m}$}

First, the empirical relationships are derived and the correlations between radar measurements and $D_{m}$ are compared for the combined OLYMPEX, MC3E, and GCPEX IOPs, hereafter referred to as the "composite dataset." Empirical relationships derived from the composite dataset are referred to as the "composite empirical relationships." The composite data and composite empirical relationships for $Z_{\mathrm{Ku}}, Z_{\mathrm{Ka}}$, and DWR are presented in Fig. 3. Regression parameters for the composite empirical relationships are provided in a supplemental table. All results in this section only refer to the composite dataset. Noted differences in correlations between $Z-D_{m}$ and DWR $-D_{m}$ relationships do not always apply for collocated data from different experiments or IOPs.

DWR and $D_{m}$ from the composite dataset are better correlated and less heteroscedastic than $Z_{\mathrm{Ku}}$ and $D_{m}$. Less
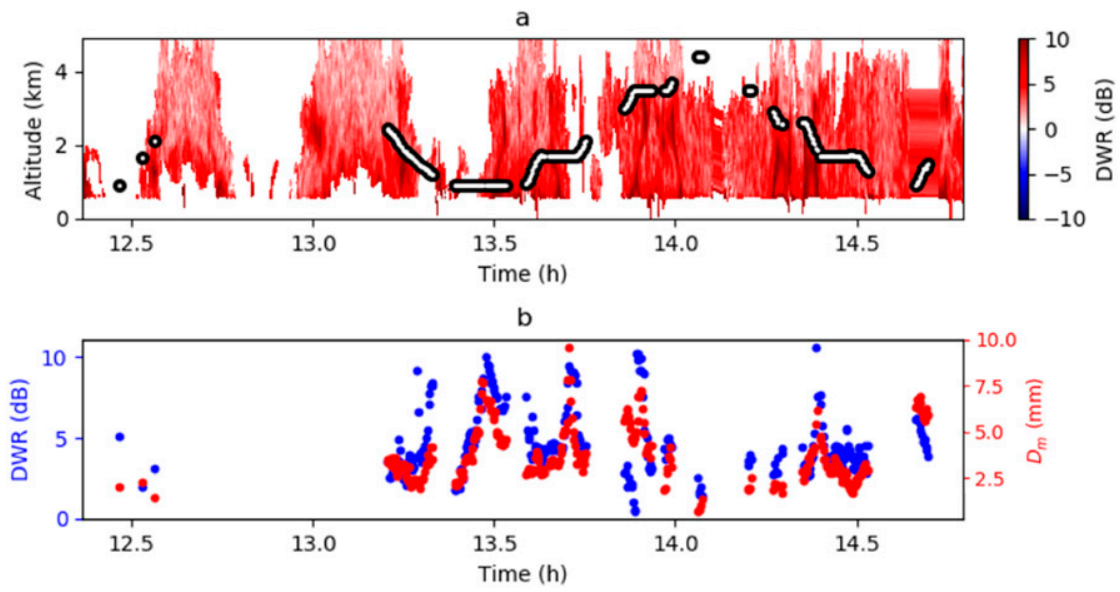

FIG. 2. A visualization of collocated data during the G0224 IOP. (a) The altitude of the UND-Citation (points) during simultaneous DWR profiles (shaded, in dB; color bar at right), and (b) time series of collocated DWR (dB) and $D_{m}(\mathrm{~mm})$ measurements in blue (left axis) and red (right axis), respectively. 

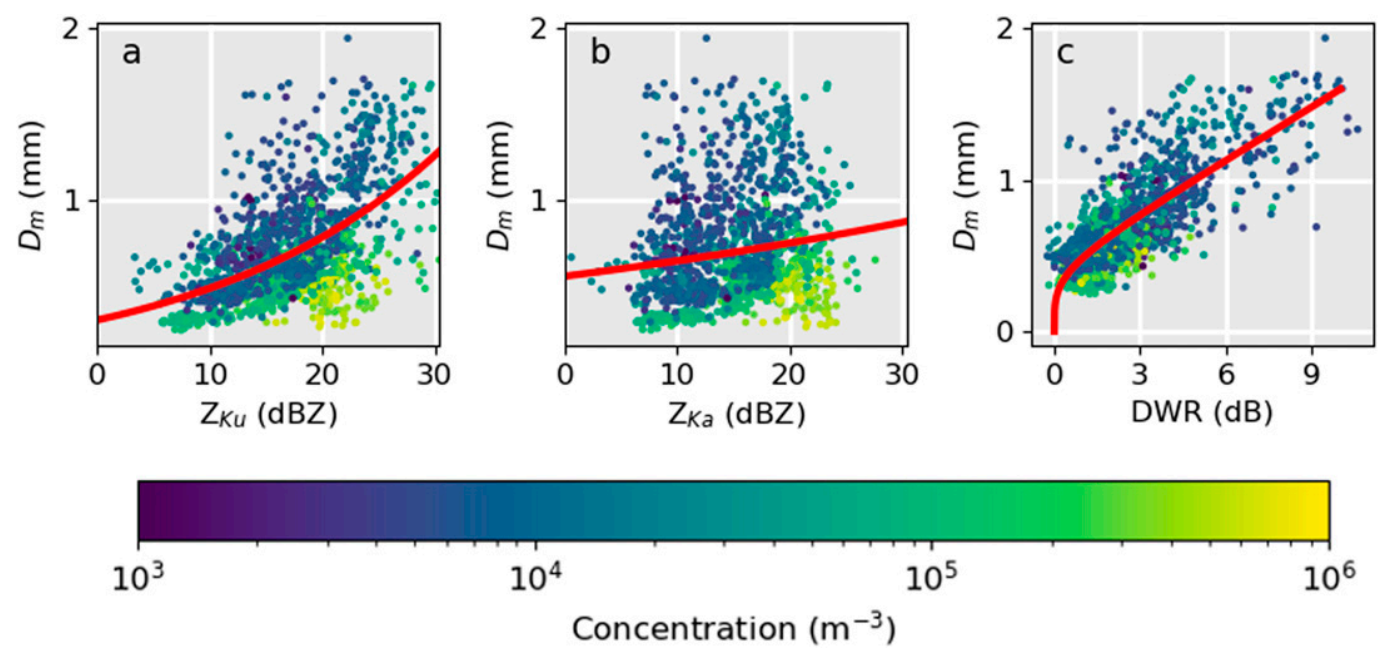

FIG. 3. Scatterplots of collocated radar measurements and $D_{m}$ : (a) $Z_{\mathrm{Ku}}$, (b) $Z_{\mathrm{Ka}}$, and (c) DWR. Scattered data are colored by $N_{t}$. Empirical relationships between radar measurements and $D_{m}$ are derived and plotted over the scattered data (red lines).

heteroscedasticity here refers to the observation in Fig. 3 where the spread or range of collocated measurements about the composite empirical DWR $-D_{m}$ relationship is similar at low and high DWR. On the other hand, the spread of collocated $D_{m}$ about the composite empirical $Z_{\mathrm{Ku}}-D_{m}$ relationship increases with increasing $Z_{\mathrm{Ku}}$, such that maximum $D_{m}$ values associated with $Z_{\mathrm{Ku}}$ increase from 0.75 to $2 \mathrm{~mm}$ while minimum $D_{m}$ values remain relatively constant at $0.25 \mathrm{~mm}$. Figure 3 reveals that this heteroscedasticity is linked to the total particle concentration $\left(N_{t}\right)$, calculated from in situ PSDs through

$$
N_{t}=\int_{D_{\min }}^{D_{\max }} n(D) d D
$$

Specifically, the heteroscedasticity of the $Z_{\mathrm{Ku}}-D_{m}$ data appear to be associated with a set of data points with $D_{m}<0.75 \mathrm{~mm}$ and $N_{t}>10^{5} \mathrm{~m}^{-3}$ that have disproportionately high $Z$ compared to other data points with the same $D_{m}$ at lower $N_{t}$. This link between $N_{t}$ and heteroscedasticity also explains why the data appear homoscedastic, especially in comparison to $Z_{\mathrm{Ku}}$ and $D_{m}$. DWR and $D_{m}$ are both theoretically insensitive to $N_{t}$ so the relationship between the two should not be impacted by changes in $N_{t}$.

The values of $Z_{\mathrm{Ka}}$ and $D_{m}$ from the composite dataset are poorly correlated $(\rho=0.19)$. We note that $Z_{\mathrm{Ka}}$ measurements are rarely, if ever, used as sole measurements for satellite frozen precipitation retrievals in research. However, since CloudSat operates at a W-band wavelength that is narrower and more prone to non-Rayleigh scattering effects than the $Z_{\mathrm{Ka}}$ measurements used in this study, this result suggests that CloudSat reflectivity measurements could have little correlation with $D_{m}$ in clouds that are observable by GPM.

\section{c. Sensitivity of empirical relationships to different environmental conditions}

In this subsection, $Z_{\mathrm{Ku}}-D_{m}$ and DWR- $D_{m}$ empirical relationships derived from data subsets representing different environmental conditions are compared. Specifically, these environmental conditions refer to differences in temperatures ranges [section $4 c(1)$ ], the average conditions observed in the three $\mathrm{GV}$ experiments [section 4c(2)], and cloud types observed in the individual IOPs during the three experiments [section $4 \mathrm{c}(3)]$. The $Z_{\mathrm{Ka}}-D_{m}$ results tend to be similar to the $Z_{\mathrm{Ku}}-D_{m}$ results, just with lower correlation, so only the $Z_{\mathrm{Ku}}-D_{m}$ results are shown. Tables in the online supplemental material provide regression values for derived empirical relationships and ranges of temperature, $D_{m}, Z_{\mathrm{Ku}}$, and DWR corresponding to each data subset.

\section{1) EMPIRICAL RELATIONSHIPS IN DIFFERENT TEMPERATURE REGIMES}

Figure 4 shows the $Z_{\mathrm{Ku}}-D_{m}$ and DWR- $D_{m}$ data and empirical relationships in different temperature ranges. These ranges are referred to as $T_{4}\left(-40^{\circ}<T<-30^{\circ} \mathrm{C}\right), T_{3}\left(-30^{\circ}<\right.$ $\left.T<-20^{\circ} \mathrm{C}\right), T_{2}\left(-20^{\circ}<T<-10^{\circ} \mathrm{C}\right)$, and $T_{1}\left(-10^{\circ}<\right.$ $\left.T<-0^{\circ} \mathrm{C}\right)$. The data point with DWR near $6 \mathrm{~dB}$ in Fig. $4 \mathrm{e}$ is a high-influence outlier, so it is ignored when deriving the DWR $-D_{m}$ relationship for $T_{4}$. The empirical relationship in Fig. $4 \mathrm{e}$ is also truncated to a single power law to account for a low maximum DWR.

$T_{4}$ and $T_{3}$ have $D_{m}$ values that cover about half the range of $D_{m}$ measured during $T_{2}$ and $T_{1}$. A large difference in $D_{m}$ ranges between these regimes is expected, since PSDs in clouds with $T>-20^{\circ} \mathrm{C}$ allow for the growth of dendrites that can aggregate to be the largest ice particles. $Z_{\mathrm{Ku}}-D_{m}$ and DWR $-D_{m}$ relationships from different temperature ranges tend to stay close to the composite empirical relationships, with the exception of the $Z_{\mathrm{Ku}}-D_{m}$ relationship during $T_{4}$ that shows no correlation between $D_{m}$ and $Z_{\mathrm{Ku}}$ (Fig. 4a). The difference between the correlations the $Z_{\mathrm{Ku}}-D_{m}$ data and the DWR $-D_{m}$ data in Figs. $4 \mathrm{a}$ and 4 e suggests that the DWR $-D_{m}$ relationship could have particular benefits for retrieving $D_{m}$ for $T<-30^{\circ} \mathrm{C}$. However, $T_{3}$ and $T_{4}$ only represent data from 

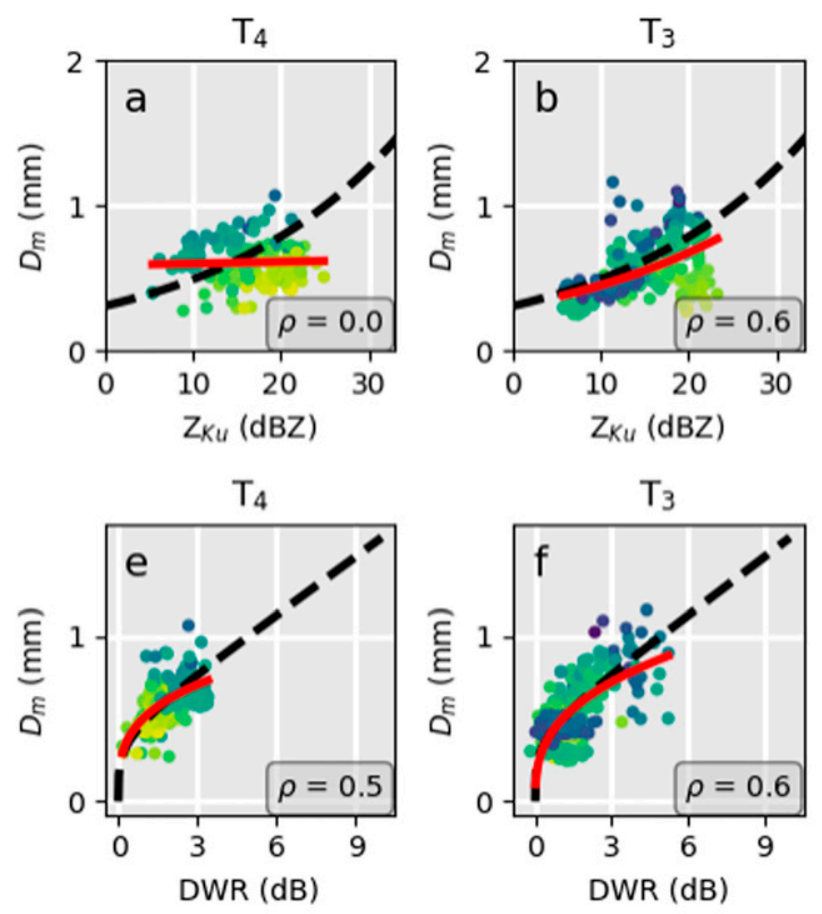
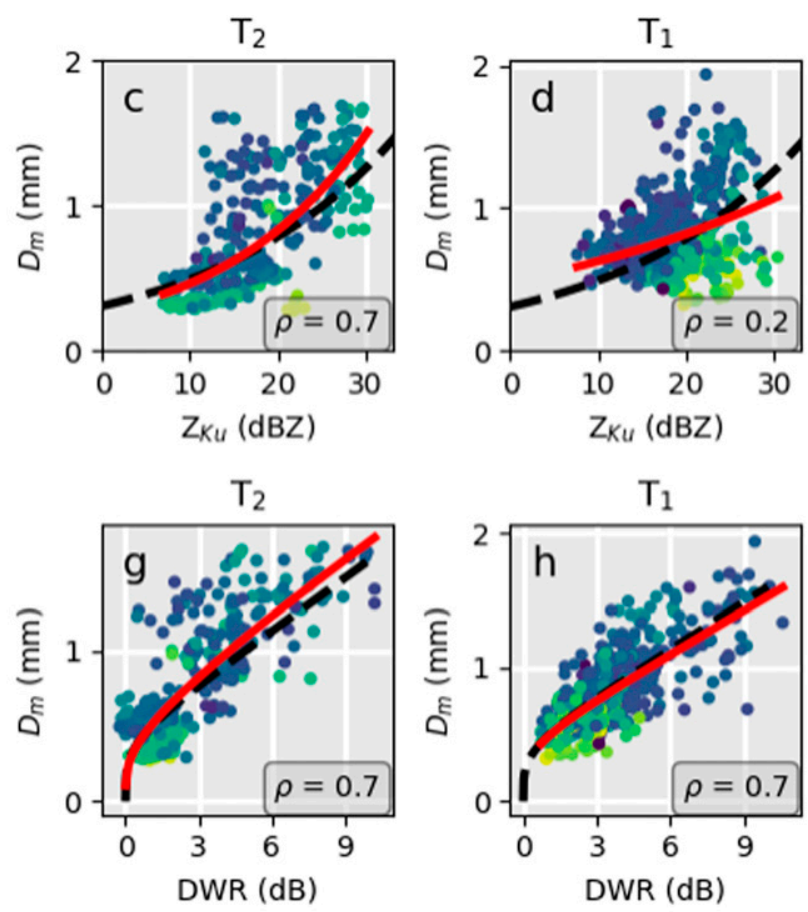

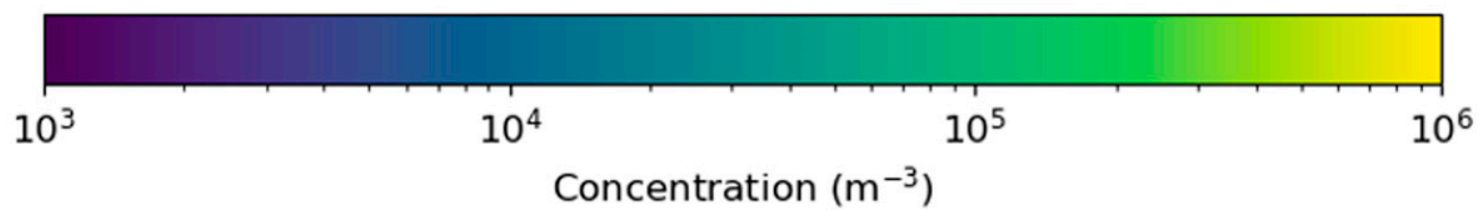

FIG. 4. Scatterplots of collocated radar measurement and $D_{m}$ : (a)-(d) $Z_{\mathrm{Ku}}$ and (e)-(h) DWR. Scattered data are colored by $N_{t}$. Empirical relationships between radar measurements and $D_{m}$ are derived and plotted over the scattered data (red lines). The black dashed line refers the composite empirical relationships. Data are separated into different temperature regimes represented by (a), (e) $T<-30^{\circ} \mathrm{C}$, (b),(f) $-20^{\circ}<T<-30^{\circ} \mathrm{C}$, (c), (g) $-10^{\circ}<T<-20 \mathrm{C}$, and (d),(h) $T>-10^{\circ} \mathrm{C}$.

two IOPs (M0425 and M0523), so more collocated data in clouds with $T<-20^{\circ} \mathrm{C}$ would be valuable to corroborate the observed correlations in this temperature regime.

\section{2) EMPIRICAL RELATIONSHIPS DURING DIFFERENT EXPERIMENTS}

Figure 5 shows the collocated data and empirical relationships for the three different $\mathrm{GV}$ experiments. As mentioned previously, many of the differences between DWR- $D_{m}$ and $Z_{\mathrm{Ku}}-D_{m}$ relationships noted in section 4 a do not apply for individual experiments. The $\rho$ between $Z_{\mathrm{Ku}}$ and $D_{m}$ is similar to the $\rho$ between DWR and $D_{m}$ from GCPEX and OLYMPEX, and the noted heteroscedasticity from the $Z_{\mathrm{Ku}}-D_{m}$ relationship is only evident from OLYMPEX. The GCPEX $Z-D_{m}$ relationships are offset toward higher $D_{m}$ relative to the OLYMPEX and MC3E $Z-D_{m}$ relationships, suggesting potential biases that could result from the application of a single $Z-D_{m}$ relationship to the different regions and seasons represented by the GV experiments.

The DWR $-D_{m}$ relationships are more similar between experiments than the $Z-D_{m}$ relationships, and they mostly provide the same predictions of $D_{m}$ from DWR as the composite relationship. The DWR $-D_{m}$ relationships from OLYMPEX and MC3E diverge from the composite relationship by up to $0.2 \mathrm{~mm}$ at the highest $\mathrm{dB}$ provided by these experiments. However, data in the range where the DWR $-D_{m}$ relationships diverge are notable sparse, and the end behavior of these DWR $-D_{m}$ relationships may be disproportionately influenced by random errors.

\section{3) EMPIRICAL RELATIONSHIPS DURING DIFFERENT IOPS}

Figures 6 and 7 provide the DWR- $D_{m}$ and $Z_{\mathrm{Ku}}-D_{m}$ collocated data from different IOPs. Ranges of DWR, $Z$, and $D_{m}$ vary considerably between IOPs, and since the fit functions were chosen with the assumption that they would be applied to large ranges of $Z_{\mathrm{Ku}}$ or DWR, attempted IOP-specific empirical relationships were often overfit and provided little scientific value for this study. Therefore, only the collocated data are presented in this section, and empirical relationships can be visually implied. Collocated data are also colored by $N_{t}$ to explain differences between empirical relationships from different IOPs.

DWR and $D_{m}$ data from different IOPs often had similar distributions. Data from G0128, M0425, M0520, M0523, and 

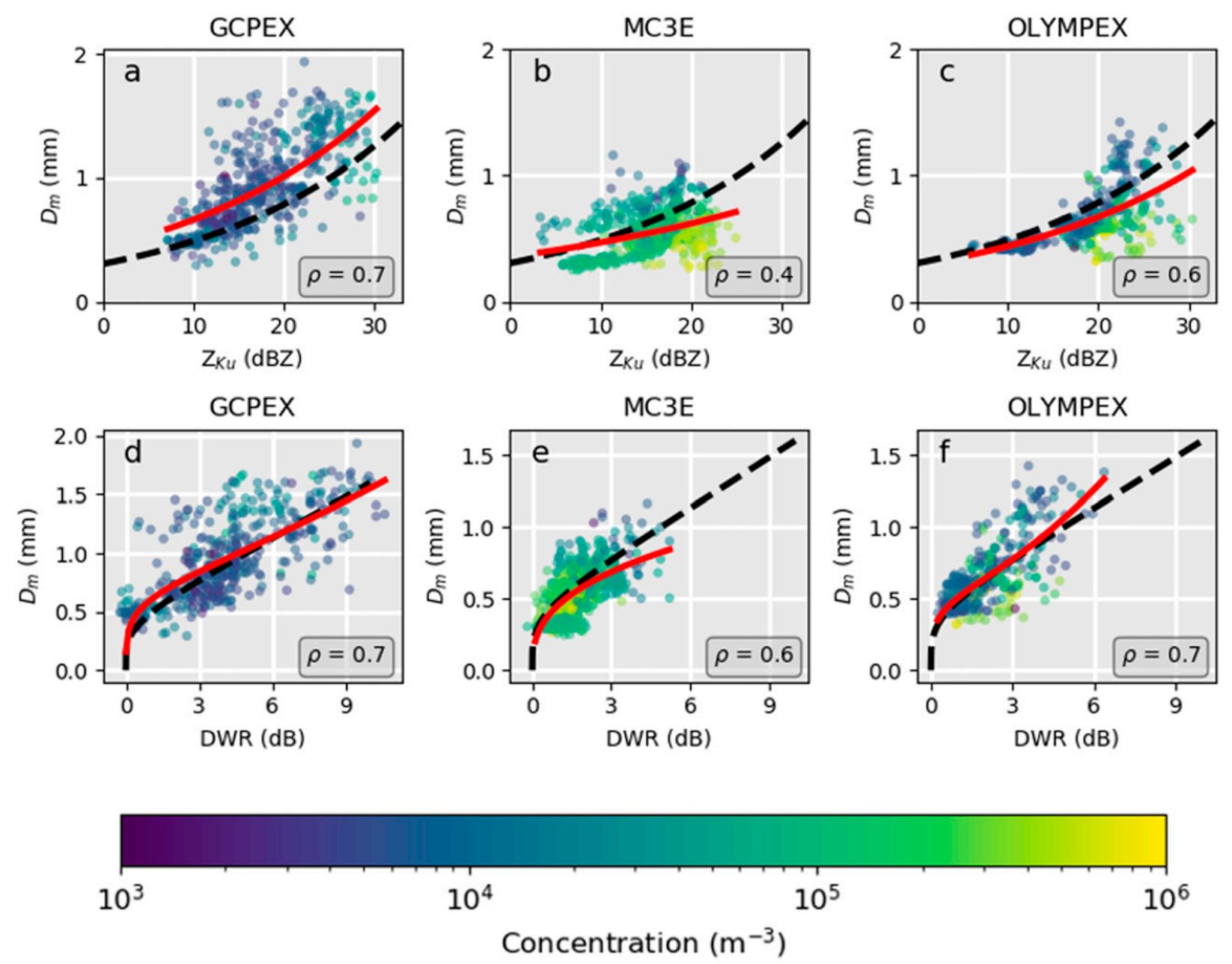

FIG. 5. As in Fig. 4, but data are separated by different experiments: (a),(d) GCPEX, (b),(e) MC3E, and (c),(f) OLYMPEX.

O1201 all had $0.25<D_{m}<1.2 \mathrm{~mm}$ and $0<$ DWR $<6 \mathrm{~dB}$, and the empirical relationships for these IOPs mostly agree with the composite relationship. The only one of these DWR- $D_{m}$ relationships that is consistently offset from the composite relationship is M0520. This may be due to differences in microphysics associated with differences in meteorology (this case sampled a broad stratiform region of a large mesoscale convective system). It may also be related to morphological differences of the ice particles, since M0520 provided the only measurements within a convective system with $T>-20^{\circ} \mathrm{C}$ where dendrites can form.

There is little similarity between the distributions of $Z_{\mathrm{Ku}}$ and $D_{m}$ among different IOPs. For example, G0128, M0523, O1201 all have similar ranges of $D_{m}\left(0.3<D_{m}<0.9 \mathrm{~mm}, 0.4<D_{m}<\right.$ $1.2 \mathrm{~mm}$, and $0.5<D_{m}<1.1 \mathrm{~mm}$, respectively) but widely differing ranges of $Z_{\mathrm{Ku}}\left(6<Z_{\mathrm{Ku}}<13 \mathrm{~dB} Z, 1<Z_{\mathrm{Ku}}<29 \mathrm{~dB} Z\right.$, $16<Z_{\mathrm{Ku}}<23 \mathrm{~dB} Z$, respectively). There is a very high correlation between $Z_{\mathrm{Ku}}$ and $D_{m}$ during M0520 ( $\left.\rho=0.9\right)$ but they are totally uncorrelated during M0523 and M0425. Again, M0520 was also the only MC3E IOP that predominantly sampled PSDs for $T>-20^{\circ} \mathrm{C}$, whereas M0523 and M0425 sampled clouds with $T<-20^{\circ} \mathrm{C}$ where nondendritic crystal habits tend to dominate IOPs and higher $N_{t}$ were observed. This shows that the $Z-D_{m}$ relationship can be impacted by environmental factors that vary during and between different IOPs while the DWR $-D_{m}$ relationship is less affected, though there may still be some sensitivity to particle habit. The fact that the $Z-D_{m}$ relationship of the IOPs with the highest $N_{T}$ are all offset farthest below the empirical relationship also suggest that more accurate $Z-D_{m}$ relationships may be predictable for different environmental conditions if those conditions can be associated with tendencies of $N_{t}$. However, during GCPEX no $N_{t}$ sensitivity is visible, and it is not immediately apparent why the $Z-D_{m}$ relationship is offset toward higher $D_{m}$ for $N_{t}$ values that are associated with lower $D_{m}$ during other experiments

\section{d. Retrieval evaluations}

In this subsection, the composite empirical relationships are evaluated for their ability to retrieve $D_{m}$. Collocated measurements are separated into categories of field experiment, IOP, and temperature range. The RMSE and bias corresponding to the retrievals from different subsets are presented in Fig. 8. 

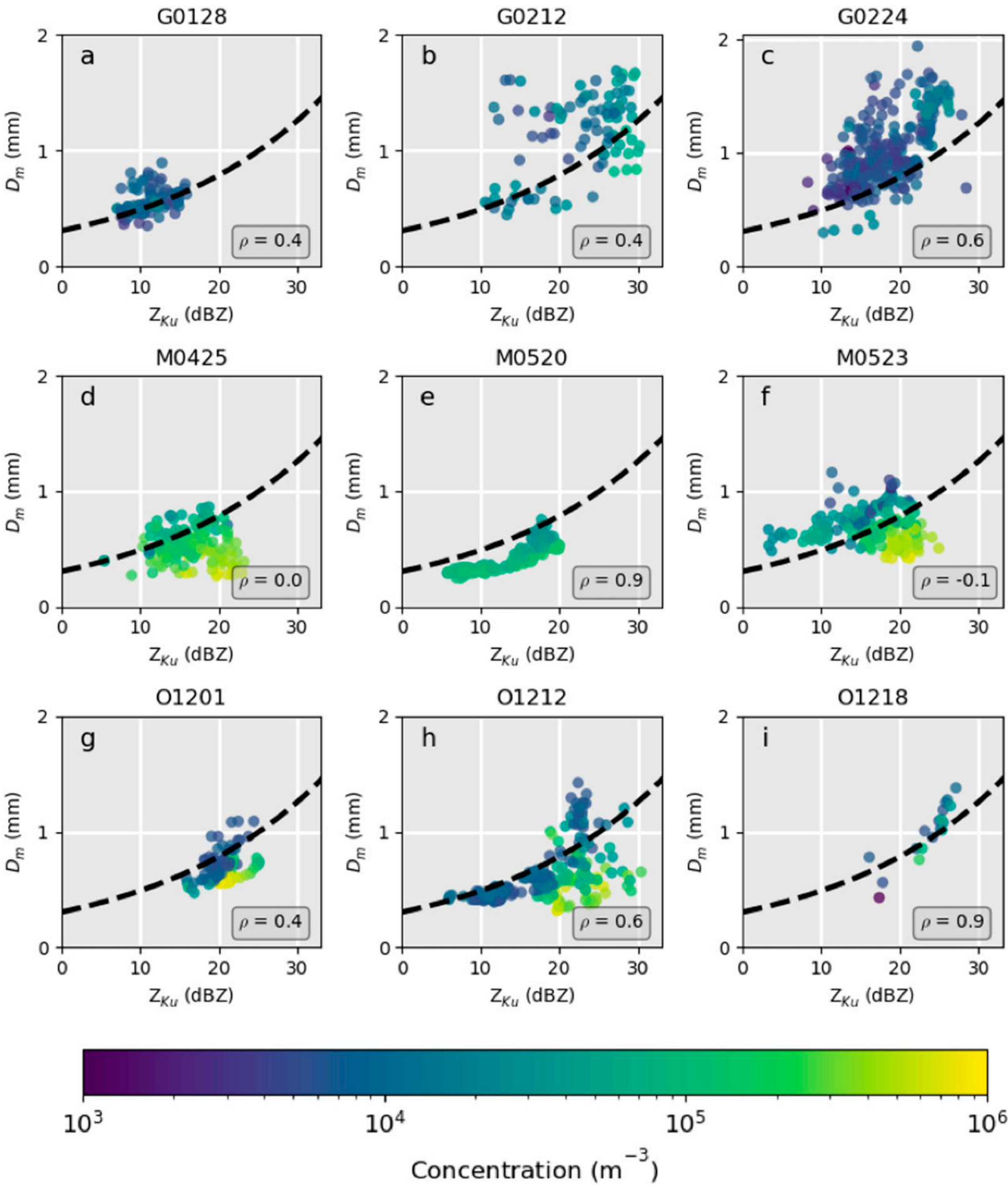

FIG. 6. Collocated DWR and $D_{m}$ are presented as scatterplots and colored by $N_{t}$. Data are separated by IOP, as labeled in each panel title. The black dashed line refers to the composite empirical $Z_{\mathrm{Ku}}-D_{m}$ relationship.

Judging by the bias and RMSE values, the DWR $-D_{m}$ retrieval provides demonstrably superior retrievals to $Z-D_{m}$ retrievals. With respect to the complete dataset, DWR $-D_{m}$ retrievals have a decreased RMSE $(0.19 \mathrm{~mm})$ compared to $Z_{\mathrm{Ku}}-D_{m}$ retrievals $(0.25 \mathrm{~mm})$ and $Z_{\mathrm{Ka}}-D_{m}$ retrievals $(0.3 \mathrm{~mm})$. With the exception of G0128 and O1218, DWR $-D_{m}$ retrievals have a decreased RMSE across data subsets as well. O1218 was based on a relatively low number of data points, 

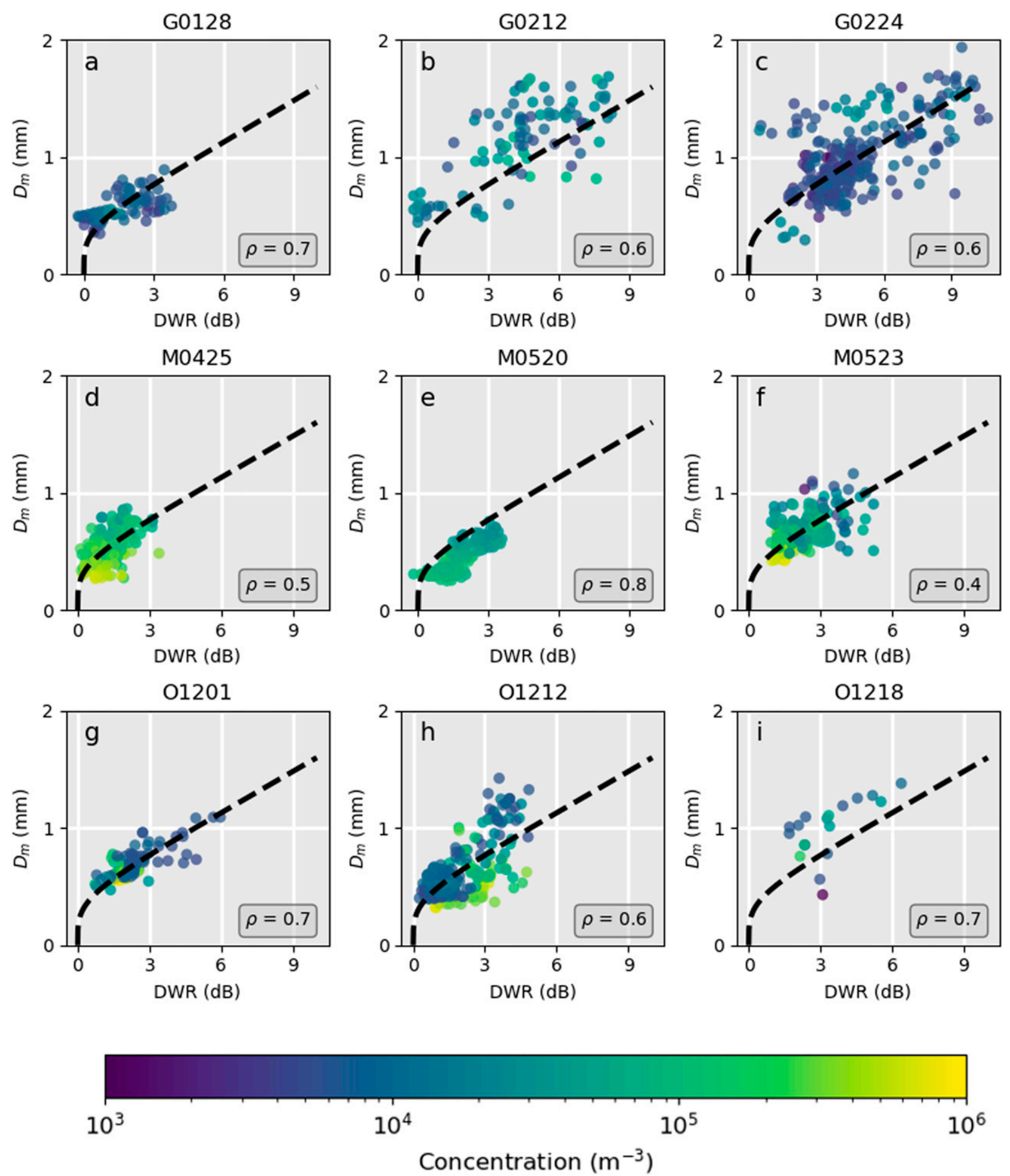

FIG. 7. As in Fig. 6, but with $Z_{\mathrm{Ku}}$

however, so statistical results from this day are not very meaningful.

The DWR $-D_{m}$ retrievals also have a lower bias across data subsets than the $Z-D_{m}$ retrievals. The range of biases between experiments from the DWR $-D_{m}$ relationship was $0.11 \mathrm{~mm}$, almost a third lower in RMSE than the range of biases between experiments from the $Z_{\mathrm{Ku}}-D_{m}$ relationship $(0.32 \mathrm{~mm})$. Following a prediction from section $3 \mathrm{c}(1)$, the $\mathrm{DWR}-D_{m}$ retrieval also provides a stronger decrease in bias for $T<-20^{\circ} \mathrm{C}$ than for $T>-20^{\circ} \mathrm{C}$. These differences in bias can often be very 

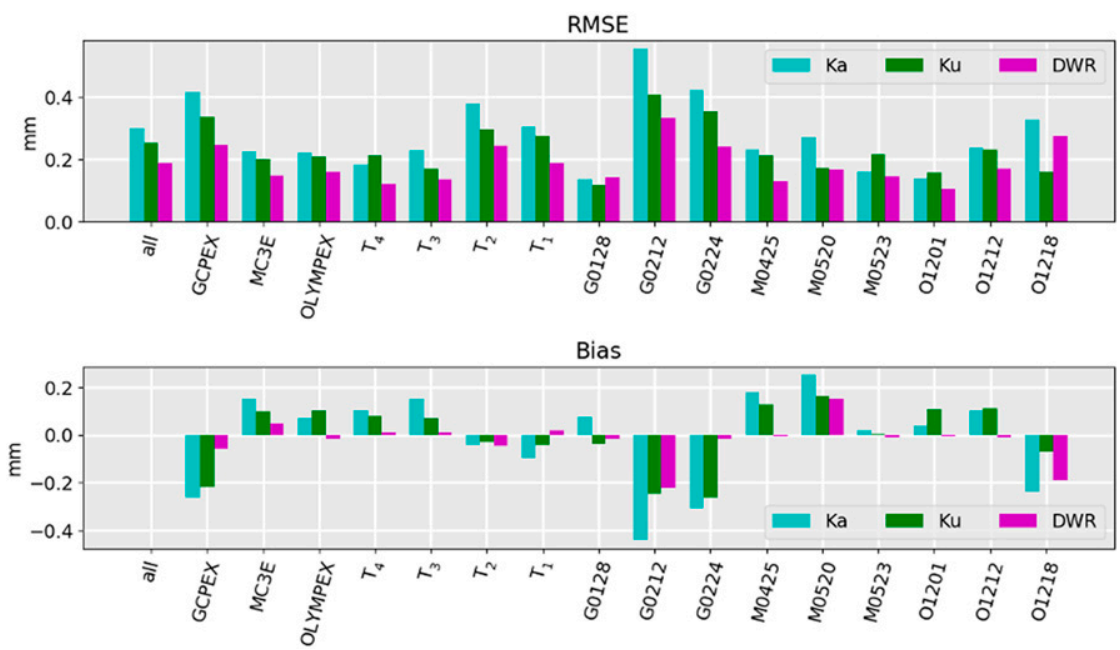

FIG. 8. (top) RMSE and (bottom) bias resulting from different radar retrievals of $D_{m}$. $D_{m}$ is retrieved using the empirical relationships from section $3 \mathrm{~b}$.

strong; the bias from the DWR $-D_{m}$ retrieval is less than $10 \%$ the bias from the $Z-D_{m}$ retrieval in four out of nine IOPs.

\section{Application for GPM retrievals}

The 2A-DPR retrieval algorithm that retrieves $D_{m}$ from DPR measurements currently relies on simulated relationships between DWR and $D_{m}$, whereby a constant-density spherical scattering model is applied to model PSDs to construct a lookup table of DWR and $D_{m}$ values (Seto et al. 2013). This relationship is already recognized to be a poor representation of DWR $-D_{m}$ relationships for most nonspherical ice PSDs (Petty and Huang 2010; Leinonen et al. 2012), but it is also difficult to objectively recommend an improved model. Fundamentally different scattering models have demonstrated similar worth for recreating multiple-frequency reflectivity of ice PSDs in different environmental settings (Kneifel et al. 2015) and each of these scattering models require numerous microphysical parameterizations that are still poorly understood for natural ice crystals (Jiang et al. 2017; Finlon et al. 2019). With little reason to prefer a particular model or parameterization, there are a large number of DWR $-D_{m}$ relationships with that can be recommended in singular global retrieval models with similar justification (Leinonen et al. 2018a).

The composite DWR $-D_{m}$ relationship presented here represents a novel and singular alternative method to retrieve $D_{m}$ from GPM measurements that provides minimally biased retrievals in diverse environmental conditions. The composite DWR $-D_{m}$ relationship appears linear, and a first-order regression would arguably be a functionally equivalent relationship for retrieval purposes. However, such a relationship would violate boundary conditions required by physics. The relationship must intercept the origin, and a first-order relationship would have a nonzero y intercept. For this reason, the double power law is still preferred. In practice a function that predicts unphysical negative values for $D_{m}$ is necessary to ensure that the average of random DWR instrument noise about zero leads to a $D_{m}>0$. The complete form of the composite DWR $-D_{m}$ relationship recommended for DPR satellite retrievals is therefore presented as

$$
D_{m}=\left\{\begin{array}{ll}
0.43 \mathrm{DWR}{ }^{0.25}+0.06 \mathrm{DWR}^{1.17}, & \mathrm{DWR}>=0 \\
-0.43|\mathrm{DWR}|^{0.25}-0.06|\mathrm{DWR}|^{1.17}, & \mathrm{DWR}<0
\end{array} .\right.
$$

The composite DWR $-D_{m}$ relationship demonstrates good agreement with $D_{m}$ predictions from simulated DWR- $D_{m}$ different homogeneous and heterogeneous scattering models that have been recommended in recent literature (Leinonen et al. 2018b; Hogan et al. 2017; Leinonen et al. 2018a; Tyynelä et al. 2011; Mason et al. 2018). In Fig. 9, the composite DWR $-D_{m}$ relationship is compared with simulated relationships from spheroidal, dendrite aggregate, and needle aggregate scattering models. Reflectivity is calculated as

$$
Z_{\lambda}=\left(\frac{\varepsilon_{\lambda}+2}{\varepsilon_{\lambda}-1}\right)^{2} \frac{\lambda^{4}}{\pi^{5}} \int_{D_{\min }}^{D_{\max }} n(D) \sigma_{b}(D) d D
$$

with $\varepsilon_{\lambda}$ representing the dielectric constant of water at a given wavelength, $\sigma_{b}(D)$ representing the backscattered cross-section distribution of ice particles, and $\lambda$ representing the radar wavelength. Dendrite aggregate and needle aggregates are simulated using the self-similar Rayleigh-Gans approximation (Hogan et al. 2017) with habit-specific parameters drawn from Mason et al. (2019). Spheroids are simulated with the PyTmatrix package (Leinonen 2014), incorporating the shape and orientation parameterizations for ice particles from Hogan et al. (2012). All simulated relationships use the same Heymsfield et al. (2010) mass-diameter relationship used to calculate $D_{m}$. PSDs are represented by an exponential function that Liao et al. (2016) deemed satisfactory to represent frozen PSDs with reflectivities above the DPR minimum detectable reflectivity,

$$
n(D)=N_{0} e^{-\left(4 / D_{m}\right) D},
$$




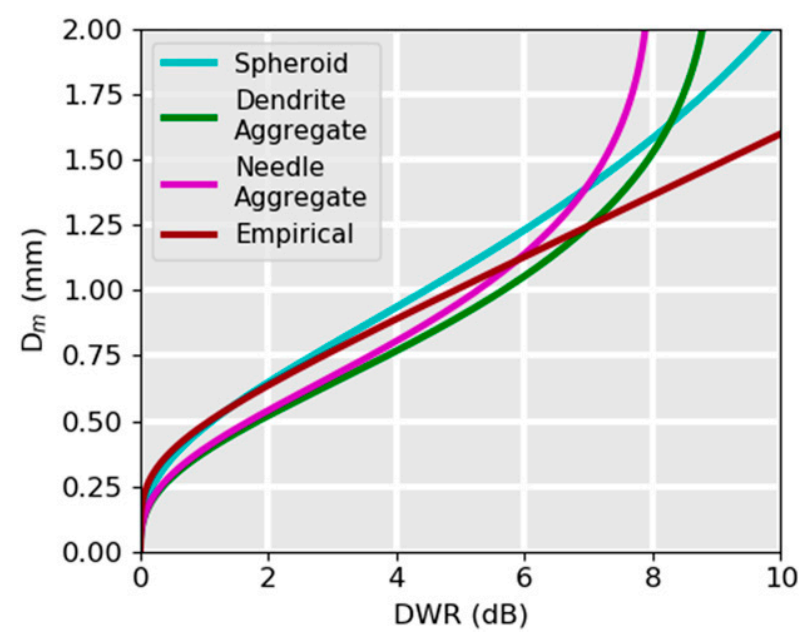

FIG. 9. The composite DWR $-D_{m}$ relationship is compared with simulated DWR $-D_{m}$ relationships representing different simulated ice particle shapes. The spheroid model is constructed with PyTmatrix (Leinonen 2014); needle and dendrite aggregates are constructed using the self-similar Rayleigh-Gans approximation (Hogan et al. 2017)

with $N_{0}$ representing the intercept parameter. The parameterization of $N_{0}$ is inconsequential for calculations of DWR and $D_{m}$, and $D_{m}$ spans the $0-10 \mathrm{~mm}$ range observed in this study.

The empirical DWR $-D_{m}$ relationship provides retrievals of $D_{m}$ within $0.2 \mathrm{~mm}$ of the fractal and spheroidal scattering models up to $8 \mathrm{~dB}$. Beyond this point, DWR $-D_{m}$ relationships diverge. Unfortunately, the GV data in this study set did not provide a large number of high DWR collocations, and most of the high DWR data that are provided come from repeated passes through singular cloud features during GCPEX. Therefore, the empirical relationship represents a considerably less diverse set of data at high DWR than lower DWR, where all IOPs contribute to the regression. Furthermore, the DWR $-D_{m}$ relationship may not be valid for DWR and $D_{m}$ values greater or lower than those observed during the experiments. A poor representation of high DWR measurements is a noted deficiency of the composite DWR $-D_{m}$ relationship, but it can hopefully be improved with collocated observations from future field experiments.

\section{Conclusions}

In this study, empirically generated relationships between dual-frequency radar measurements $\left(Z_{\mathrm{Ku}}, Z_{\mathrm{Ka}}\right.$, DWR) and the $D_{m}$ of frozen precipitation were generated from a dataset that consisted of collocated in situ measurements of cloud microphysical properties within volumes remotely sensed by airborne radar from three experiments and nine IOPs. These experiments sampled winter synoptic and lake-effect storms near Ontario (GCPEX), winter orographic and synoptic storms near the Olympic Mountain (OLYMPEX), and warm season convective storms in Oklahoma (MC3E). A form of the DWR$D_{m}$ relationship derived from this composite dataset that can be used for DPR precipitation retrievals is provided by Eq. (8).
The DWR and $D_{m}$ from the composite dataset had a stronger correlation $(\rho=0.77)$ than $Z_{\mathrm{Ku}}$ and $D_{m}(\rho=0.52)$ or $Z_{\mathrm{Ka}}$ and $D_{m}(\rho=0.19)$. DWR and $D_{m}$ from the composite dataset were also more homoscedastic than $Z_{\mathrm{Ku}}$ and $D_{m}$. The differences in heteroscedasticity between the two radar measurements is related to an observed sensitivity of the $Z-D_{m}$ relationships to $N_{t}$ that is not experienced by DWR. Clouds with a higher $N_{t}$ will have higher $Z$ associated with lower $D_{m}$.

When the $D_{m}$ retrieved by the derived relation were directly compared to in situ-measured $D_{m}$, the RMSE from the DWR$D_{m}$ and $Z_{\mathrm{Ku}}-D_{m}$ retrievals were 0.25 and $0.19 \mathrm{~mm}$, respectively. The range of retrieval biases between experiments from the DWR $-D_{m}$ relationship (0.11) was almost a third the range of biases between experiments from the $Z_{\mathrm{Ku}}-D_{m}$ relationship $(0.32)$, and the bias from the DWR $-D_{m}$ retrieval was less than $10 \%$ the bias from the $Z-D_{m}$ retrieval in four out of nine IOPs. Together, these results demonstrate that the DWR measurements provided by DPR can offer a more precise and unbiased retrieval of $D_{m}$, with a more consistent accuracy across the range of retrievable $D_{m}$, than measurements from $Z$ alone.

One of the biggest limitations of this study was a relatively low number of IOPs over only three different regions that provided DWR $-D_{m}$ collocations, leading to inconsistent diversity of data in different regions and measurement limits. Measurements with $D_{m}>1 \mathrm{~mm}$ were mostly provided by just two GCPEX IOPs, and measurements with $T<-20^{\circ} \mathrm{C}$ were mostly provided by just two MC3E IOPs. Especially in section $4 \mathrm{c}(2)$ where DWR $-D_{m}$ and $Z_{\mathrm{Ku}}-D_{m}$ relationships between different IOPs were compared, differences between empirical relationships suggested links to broader differences in microphysical conditions, but there was not enough evidence to draw confident conclusions. Follow-up studies that incorporate more experiments into the composite dataset will improve the empirical DWR $-D_{m}$ relationship as a tool for global retrieval and model evaluation. Follow-up studies would be particularly valuable to investigate the results just pertaining to $Z-D_{m}$ relationships, such as the similarity of the $Z-D_{m}-N_{t}$ relationship in different environmental conditions. Many experiments, IOPs, and continuous observation sites that provide single-wavelength radar observations and collocations could not be included in this study because they did not also supply DWR $-D_{m}$ collocations, but they could be used to make a much larger dataset for a dedicated study into $Z-D_{m}$ relationships.

It is important to emphasize that the results gathered from the composite dataset in this study were different than the results that came from single experiments, even when multiple IOPs were combined. Had only observations during GCPEX been considered, it may have been concluded that $Z$ and DWR share a similar correlation with $D_{m}$. This observation is relevant to satellite retrievals, where algorithms are often based on relationships between radar observations and microphysical properties that are determined in single experiments (Wood et al. 2013). Collocated observations between radar measurements and in situ properties from multiple experiments likely form a stronger basis for satellite retrieval algorithms that are applied uniformly to retrievals in clouds globally. More studies that combine common measurements from disparate 
experimental studies are encouraged to develop the most advantageous retrieval algorithms for satellite measurements.

Acknowledgments. George Duffy performed the work described in this paper at Vanderbilt University and has been supported by NASA Earth and Space Science Fellowship NNX14AK91H. This research was partly supported by NASA Grants NNX16AD80G to Greg McFarquhar and Stephen Nesbitt and NNX17AJ09G to Ralf Bennartz. Support was provided by the Jet Propulsion Laboratory, California Institute of Technology, under a contract with National Aeronautics and Space Administration.

Data availability statement. All experimental data come from the Global Hydrology Resources Center (GHRC) archive. Data for GV experiments used in this study can be found at https:/ghrc.nsstc.nasa.gov/pub/fieldCampaigns/gpmValidation/. Collocated PSDs and radar reflectivity, along with recalculation of results with different mass-diameter relationships, are available on request.

\section{APPENDIX}

\section{List of Acronyms}

$\begin{array}{ll}D & \begin{array}{l}\text { Any linear size of an ice particle } \\ D_{\text {meas }}\end{array} \\ \begin{array}{ll}\text { The maximum measured dimension of an ice } \\ \text { crystal from an image }\end{array} \\ \text { The diameter of a liquid droplet with the mass } \\ \text { of an ice crystal } \\ \text { DWR } & \text { Dual-Frequency Precipitation Radar } \\ \text { GPM } & \text { Dual-wavelength ratio } \\ \text { GV } & \text { Global Precipitation Measurement } \\ \text { GCPEX } & \text { Ground Validation } \\ \text { MC3E } & \text { GPM Cold Season Experiment } \\ \text { OLYMPEX } & \text { Olympititude Continental Convective Clouds } \\ \text { PSD } & \text { Particle size distribution; in this paper, "particles" } \\ Z & \text { refer to ice crystals } \\ Z & \text { Radar reflectivity }\end{array}$

\section{REFERENCES}

Adhikari, N. B., and K. Nakamura, 2002: Detectable rain range of spaceborne Ka-band radar estimated from TRMM Precipitation Radar data. J. Atmos. Oceanic Technol., 19, 1878-1885, https://doi.org/10.1175/1520-0426(2002)019<1878:DRROSK> 2.0.CO;2.

Akiyama, S., S. Shige, M. K. Yamamoto, and T. Iguchi, 2019: Heavy ice precipitation band in an oceanic extratropical cyclone observed by GPM/DPR: 1. A case study. Geophys. Res. Lett., 46, 7007-7014, https://doi.org/10.1029/2019GL082896.

Baker, B. A., and R. P. Lawson, 2006: Improvement in determination of ice water content from two-dimensional particle imagery. Part I: Image to mass relationships. J. Appl. Meteor., 45, 1282-1290, https://doi.org/10.1175/JAM2398.1.

Behrangi, A., and Coauthors, 2014: Status of high-latitude precipitation estimates from observations and reanalyses.
J. Geophys. Res. Atmos., 121, 4468-4486, https://doi.org/ 10.1002/2015JD024546.

— , and Coauthors, 2016: Status of high-latitude precipitation estimates from observations and reanalyses. J. Geophys. Res. Atmos., 121, 4468-4486, https://doi.org/10.1002/2015jd024546.

Bennartz, R., F. Fell, D. Schuettemeyer, R. Bennartz, C. Pettersen, and M. D. Shupe, 2019: Spatial and temporal variability of snowfall over Greenland from CloudSat observations. Atmos. Chem. Phys., 19, 8101-8121, https://doi.org/10.5194/acp-198101-2019.

Borque, P., K. J. Harnos, S. W. Nesbitt, and G. M. McFarquhar, 2019: Improved parameterization of ice particle size distributions using uncorrelated mass spectrum parameters: Results from GCPEx. J. Appl. Meteor. Climatol., 58, 16571676, https://doi.org/10.1175/JAMC-D-18-0203.1.

Chase, R. J., and Coauthors, 2018: Evaluation of triple-frequency radar retrieval of snowfall properties using coincident airborne in situ observations during OLYMPEX. Geophys. Res. Lett., 45, 5752-5760, https://doi.org/10.1029/2018GL077997.

- S. W. Nesbitt, and G. M. McFarquhar, 2020: Evaluation of the microphysical assumptions within GPM-DPR using groundbased observations of rain and snow. Atmosphere, 11, 619, https://doi.org/10.3390/atmos11060619.

Colle, B. A., D. Stak, and S. E. Yuter, 2014: Surface microphysical observations within East Coast winter storms on Long Island, New York. Mon. Wea. Rev., 142, 3126-3146, https://doi.org/ 10.1175/MWR-D-14-00035.1.

Ding, S., G. M. McFarquhar, S. W. Nesbitt, R. Chase, M. R. Poellot, and H. Wang, 2020: The dependence of mass-dimensional relationships on median mass diameter. Atmosphere, 11, 756, https:// doi.org/10.3390/atmos11070756.

Duffy, G., and R. Bennartz, 2018: The role of melting snow in the ocean surface heat budget. Geophys. Res. Lett., 45, 9782-9789, https://doi.org/10.1029/2018GL079182.

Finlon, J. A., G. M. McFarquhar, S. W. Nesbitt, R. M. Rauber, H. Morrison, W. Wu, and P. Zhang, 2019: A novel approach for characterizing the variability in mass-dimension relationships: Results from MC3E. Atmos. Chem. Phys., 19, 3621-3643, https:// doi.org/10.5194/acp-19-3621-2019.

Heymsfield, A. J., and J. L. Parrish, 1978: A computational technique for increasing the effective sampling volume of the PMS twodimensional particle size spectrometer. J. Appl. Meteor., 17, 1566-1572, https://doi.org/10.1175/1520-0450(1978)017<1566: ACTFIT $>2.0 . \mathrm{CO} ; 2$.

_ C. Schmitt, A. Bansemer, and C. H. Twohy, 2010: Improved representation of ice particle masses based on observations in natural clouds. J. Atmos. Sci., 67, 3303-3318, https://doi.org/ 10.1175/2010JAS3507.1.

Hiley, M. J., M. S. Kulie, and R. Bennartz, 2011: Uncertainty analysis for CloudSat snowfall retrievals. J. Appl. Meteor. Climatol., 50, 399-418, https://doi.org/10.1175/2010JAMC2505.1.

Hogan, R. J., L. Tian, P. R. A. Brown, C. D. Westbrook, A. J. Heymsfield, and J. D. Eastment, 2012: Radar scattering from ice aggregates using the horizontally aligned oblate spheroid approximation. J. Appl. Meteor. Climatol., 51, 655-671, https:// doi.org/10.1175/jamc-d-11-074.1.

_ _ R. Honeyager, J. Tyynelä, and S. Kneifel, 2017: Calculating the millimetre-wave scattering phase function of snowflakes using the self-similar Rayleigh-Gans approximation. Quart. J. Roy. Meteor. Soc., 143, 834-844, https://doi.org/10.1002/qj.2968.

Hou, A. Y., and Coauthors, 2014: The Global Precipitation Measurement mission. Bull. Amer. Meteor. Soc., 95, 701-722, https://doi.org/10.1175/BAMS-D-13-00164.1. 
Houze, R. A., Jr., and Coauthors, 2017: The Olympic Mountains Experiment (OLYMPEX). Bull. Amer. Meteor. Soc., 98, 2167-2188, https://doi.org/10.1175/bams-d-16-0182.1.

Huang, G. J., V. N. Bringi, A. J. Newman, G. Lee, D. Moisseev, and B. M. Notaroš, 2019: Dual-wavelength radar technique development for snow rate estimation: A case study from GCPEx. Atmos. Meas. Tech., 12, 1409-1427, https://doi.org/ 10.5194/amt-12-1409-2019.

Jackson, R. C., and Coauthors, 2012: The dependence of ice microphysics on aerosol concentration in arctic mixed-phase stratus clouds during ISDAC and M-PACE. J. Geophys. Res., 117, D15207, https://doi.org/10.1029/2012JD017668.

Jensen, M. P., and Coauthors, 2016: The Midlatitude Continental Convective Clouds Experiment (MC3E). Bull. Amer. Meteor. Soc., 97, 1667-1686, https://doi.org/10.1175/bams-d-14-00228.1.

Jiang, Z., M. Oue, J. Verlinde, E. E. Clothiaux, K. Aydin, G. Botta, and Y. Lu, 2017: What can we conclude about the real aspect ratios of ice particle aggregates from two-dimensional images? J. Appl. Meteor. Climatol., 56, 725-734, https://oi.org/10.1175/ JAMC-D-16-0248.1.

Kneifel, S., M. S. Kulie, and R. Bennartz, 2011: A triple-frequency approach to retrieve microphysical snowfall parameters. J. Geophys. Res., 116, D11203, https://doi.org/10.1029/ 2010JD015430.

- - A. von Lerber, J. Tiira, D. Moisseev, P. Kollias, and J. Leinonen, 2015: Observed relations between snowfall microphysics and triple-frequency radar measurements. J. Geophys. Res. Atmos., 120, 6034-6055, https://doi.org/ 10.1002/2015JD023156.

Kollias, P., E. E. Clothiaux, M. A. Miller, B. A. Albrecht, G. L. Stephens, and T. P. Ackerman, 2007: Millimeter-wavelength radars: New frontier in atmospheric cloud and precipitation research. Bull. Amer. Meteor. Soc., 88, 1608-1624, https:// doi.org/10.1175/BAMS-88-10-1608.

Kulie, M. S., L. Milani, N. B. Wood, S. A. Tushaus, R. Bennartz, and T. S. L'Ecuyer, 2016: A shallow cumuliform snowfall census using spaceborne radar. J. Hydrometeor., 17, 12611279, https://doi.org/10.1175/JHM-D-15-0123.1.

Kummerow, C., and Coauthors, 2000: The status of the Tropical Rainfall Measuring Mission (TRMM) after two years in orbit. J. Appl. Meteor., 39, 1965-1982, https://doi.org/10.1175/15200450(2001)040<1965:TSOTTR > 2.0.CO;2.

Leinonen, J., 2014: High-level interface to T-matrix scattering calculations: Architecture, capabilities and limitations. Opt. Express, 22, 1655, https://doi.org/10.1364/oe.22.001655.

— , and W. Szyrmer, 2015: Radar signatures of snowflake riming: A modeling study. Earth Space Sci., 2, 346-358, https://doi.org/ 10.1002/2015ea000102.

__, S. Kneifel, D. Moisseev, J. Tyynelä, S. Tanelli, and T. Nousiainen, 2012: Evidence of nonspheroidal behavior in millimeter-wavelength radar observations of snowfall. J. Geophys. Res., 117, D18205, https://doi.org/10.1029/ 2012JD017680.

_ , and Coauthors, 2018a: Retrieval of snowflake microphysical properties from multifrequency radar observations. Atmos. Meas. Tech., 11, 5471-5488, https://doi.org/10.5194/amt-11-5471-2018.

— - S. Kneifel, and R. J. Hogan, 2018b: Evaluation of the Rayleigh-Gans approximation for microwave scattering by rimed snowflakes. Quart. J. Roy. Meteor. Soc., 144, 77-88, https://doi.org/10.1002/qj.3093.

Li, L., and Coauthors, 2016: The NASA High-Altitude Imaging Wind and Rain Airborne Profiler. IEEE Trans. Geosci. Remote Sens., 54, 298-310, https://doi.org/10.1109/TGRS.2015.2456501.
Li, N., Z. Wang, X. Chen, and G. Austin, 2019: Studies of general precipitation features with TRMM PR data: An extensive overview. Remote Sens., 11, 80, https://doi.org/10.3390/rs11010080.

Liao, L., R. Meneghini, L. Tian, and G. M. Heymsfield, 2008: Retrieval of snow and rain from combined X- and W-band airborne radar measurements. IEEE Trans. Geosci. Remote Sens., 46, 1514-1524, https://doi.org/10.1109/TGRS.2008.916079.

,,-- A. Tokay, and L. F. Bliven, 2016: Retrieval of snow properties for Ku- and Ka-band dual-frequency radar. J. Appl. Meteor. Climatol., 55, 1845-1858, https://doi.org/10.1175/ JAMC-D-15-0355.1.

Liu, G., 2009: Deriving snow cloud characteristics from CloudSat observations. J. Geophys. Res., 113, D00A09, https://doi.org/ 10.1029/2007JD009766.

Mason, S. L., C. J. Chiu, R. J. Hogan, D. Moisseev, and S. Kneifel, 2018: Retrievals of riming and snow density from vertically pointing Doppler radars. J. Geophys. Res. Atmos., 123, 13 80713 834, https://doi.org/10.1029/2018JD028603.

_ , R. J. Hogan, C. D. Westbrook, S. Kneifel, D. Moisseev, and L. von Terzi, 2019: The importance of particle size distribution and internal structure for triple-frequency radar retrievals of the morphology of snow. Atmos. Meas. Tech., 12, 4993-5018, https://doi.org/10.5194/amt-12-4993-2019.

Matrosov, S. Y., 1998: A dual-wavelength radar method to measure snowfall rate. J. Appl. Meteor., 37, 1510-1521, https://doi.org/ 10.1175/1520-0450(1998)037<1510:ADWRMT>2.0.CO;2.

_ 2007: Modeling backscatter properties of snowfall at millimeter wavelengths. J. Atmos. Sci., 64, 1727-1736, https:// doi.org/10.1175/JAS3904.1.

_ , and A. J. Heymsfield, 2017: Empirical relations between size parameters of ice hydrometeor populations and radar reflectivity. J. Appl. Meteor. Climatol., 56, 2479-2488, https://doi.org/10.1175/ JAMC-D-17-0076.1.

McFarquhar, G. M., J. Um, M. Freer, D. Baumgardner, G. L. Kok, and G. Mace, 2007: Importance of small ice crystals to cirrus properties: Observations from the Tropical Warm Pool International Cloud Experiment (TWP-ICE). Geophys. Res. Lett., 34, L13803, https://doi.org/10.1029/2007GL029865.

Milani, L., and Coauthors, 2018: CloudSat snowfall estimates over Antarctica and the Southern Ocean: An assessment of independent retrieval methodologies and multi-year snowfall analysis. Atmos. Res., 213, 121-135, https://doi.org/10.1016/ j.atmosres.2018.05.015.

Mroz, K., A. Battaglia, T. J. Lang, S. Tanelli, and G. F. Sacco, 2018: Global Precipitation Measuring Dual-Frequency Precipitation Radar observations of hailstorm vertical structure: Current Capabilities and Drawbacks. J. Appl. Meteor. Climatol., 57, 2161-2178, https://doi.org/10.1175/jamc-d-18-0020.1.

Ni, X., C. Liu, and E. Zipser, 2019: Ice microphysical properties near the tops of deep convective cores implied by the GPM dual-frequency radar observations. J. Atmos. Sci., 76, 28992917, https://doi.org/10.1175/jas-d-18-0243.1.

Palerme, C., J. E. Kay, C. Genthon, T. L'Ecuyer, N. B. Wood, and C. Claud, 2014: How much snow falls on the Antarctic ice sheet? Cryosphere, 8, 1577-1587, https://doi.org/10.5194/tc-81577-2014.

—, C. Genthon, C. Claud, J. E. Kay, N. B. Wood, and T. L'Ecuyer, 2017: Evaluation of current and projected Antarctic precipitation in CMIP5 models. Climate Dyn., $\mathbf{4 8}$, 225-239, https://doi.org/10.1007/s00382-016-3071-1.

Petty, G. W., and W. Huang, 2010: Microwave backscatter and extinction by soft ice spheres and complex snow aggregates. J. Atmos. Sci., 67, 769-787, https://doi.org/10.1175/2009JAS3146.1. 
Sadowy, G. A., A. C. Berkun, W. Chun, E. Im, and S. Durden, 2003: Development of an advanced airborne precipitation radar. Microwave J., 46, 84-98.

Seto, S., T. Iguchi, and T. Oki, 2013: The basic performance of a precipitation retrieval algorithm for the Global Precipitation Measurement mission's single/dual-frequency radar measurements. IEEE Trans. Geosci. Remote Sens., 51, 52395251, https://doi.org/10.1109/TGRS.2012.2231686.

Skofronick-Jackson, G., M. Kulie, L. Milani, S. J. Munchak, N. B. Wood, and V. Levizzani, 2019: Satellite estimation of falling snow: A Global Precipitation Measurement (GPM) Core Observatory perspective. J. Appl. Meteor. Climatol., 58, 14291448, https://doi.org/10.1175/JAMC-D-18-0124.1.

Souverijns, N., and Coauthors, 2018: Evaluation of the CloudSat surface snowfall product over Antarctica using ground-based precipitation radars. Cryosphere, 12, 3775-3789, https://doi.org/ 10.5194/tc-12-3775-2018.

Stephens, G. L., and Coauthors, 2004: The CloudSat mission and the A-Train: A new dimension of space-based observations of clouds and precipitation. Bull. Amer. Meteor. Soc., 83, 1771-1790, https://doi.org/10.1175/BAMS-83-12-1771.

Tanelli, S., S. L. Durden, E. Im, K. S. Pak, D. G. Reinke, P. Partain, J. M. Haynes, and R. T. Marchand, 2008: CloudSat's cloud profiling radar after two years in orbit: Performance, calibration, and processing. IEEE Trans. Geosci. Remote Sens., 46, 3560-3573, https://doi.org/10.1109/TGRS.2008.2002030.

Tridon, F., and Coauthors, 2019: The microphysics of stratiform precipitation during OLYMPEX: Compatibility between triple-frequency radar and airborne in situ observations.
J. Geophys. Res. Atmos., 124, 8764-8792, https://doi.org/10.1029/ 2018jd029858.

Tyynelä, J., J. Leinonen, D. Moisseev, and T. Nousiainen, 2011: Radar backscattering from snowflakes: Comparison of fractal, aggregate, and soft spheroid models. J. Atmos. Oceanic Technol., 28, 1365-1372, https://doi.org/10.1175/JTECH-D11-00004.1.

Um, J., G. M. McFarquhar, Y. P. Hong, S.-S. Lee, C. H. Jung, R. P. Lawson, and Q. Mo, 2015: Dimensions and aspect ratios of natural ice crystals. Atmos. Chem. Phys., 15, 3933-3956, https://doi.org/10.5194/acp-15-3933-2015.

Williams, C. R., and Coauthors, 2014: Describing the shape of raindrop size distributions using uncorrelated raindrop mass spectrum parameters. J. Appl. Meteor. Climatol., 53, 12821296, https://doi.org/10.1175/JAMC-D-13-076.1.

Wood, N. B., T. S. L'Ecuyer, D. G. Vane, G. L. Stephens, and P. Partain, 2013: Level 2C snow profile process description and interface control document. JPL Doc., 21 pp., http:// www.cloudsat.cira.colostate.edu/sites/default/files/products/ files/2C-SNOW-PROFILE_PDICD.P_R04.20130210.pdf.

Wu, W., and G. M. McFarquhar, 2016: On the impacts of different definitions of maximum dimension for nonspherical particles recorded by $2 \mathrm{D}$ imaging probes. J. Atmos. Oceanic Technol., 33, 1057-1072, https://doi.org/10.1175/JTECH-D-15-0177.1.

Yin, M., G. Liu, R. Honeyager, and F. J. Turk, 2017: Observed differences of triple-frequency radar signatures between snowflakes in stratiform and convective clouds. J. Quant. Spectrosc. Radiat. Transfer, 193, 13-20, https://doi.org/10.1016/ j.jqsrt.2017.02.017. 